\title{
An Empirical Analysis of New \\ Rules Adopted Under Regulation \\ National Market System: Pilot \\ Phase Period Implementation Results
}

Susan L. Wright, Howard Nemiroff, and Fim Owens

A web appendix for this paper is available at:

http://dx.doi.org/10.15239/j.brcacadjb.2016.06.01.wa04

Susan L. Wright (susan.wright@oswego.edu) is an Assistant Professor at SUNY Oswego, School of Business, 310 Rich Hall, Oswego, NY 13126. Howard Nemiroff (howard.nemiroff@carleton.ca) is Associate Dean at Sprott School of Business, Carleton University, 710A Dunton Tower, 1125 Colonel By Drive, Ottawa, ON K1S5B6 Canada. Jim Owens (james.owens@maine.edu) is a Senior Research Fellow, Maine Cyber Security Cluster, c/o University of Southern Maine, Science Building 2nd Floor C-Wing, 96 Falmouth Street, Room 178, Portland, ME 04104. Correspondence concerning this paper should be directed to Susan Wright.

\begin{abstract}
We examine changes in quote competition, trade aggressiveness, trading costs, volume, and abnormal returns during the pilot
\end{abstract}


phase period of new price protection measures for both NYSE and NASDAQ stocks subject to new rules imposed under SEC Regulation NMS. We find that NYSE stocks exhibit less quote competition, increased fragmentation, and negative abnormal returns following the implementation of the new rules. Changes in trade aggressiveness and trading costs are not significant. NASDAQ stocks exhibit decreased trading costs and increased fragmentation following implementation of the new rules. These changes reflect the nature of the new regulations.

Keywords: market microstructure, market regulation, quoting behavior, market fragmentation, trading costs, trading volume, spreads

\section{INTRODUCTION}

In this study we examine aspects of Regulation NMS imposed by the Securities and Exchange Commission (SEC) on the U.S. equities markets. The new regulations were intended to improve competition in the marketplace for equity securities by allowing further automation of the trading process. The SEC believed that new regulations would increase competition among markets and among individual orders.

This study focuses on two important objectives of the new regulations: 1) to balance the competitive powers among the exchange operations competing for equity trades, and, 2) to improve the price protection available to investors. The approach taken examines changes in competition by examining quoting patterns, trading costs, market adjusted abnormal returns, and volume for NYSE and NASDAQ listings involved with the pilot phase implementation period of the new rules. The SEC selected 100 NYSE listings and 100 NASDAQ listings to participate in the pilot phase program during the summer of 2007. We examine pilot phase stocks as well as a matched sample of stocks not subject to the new rules.

We find that NYSE stocks exhibit less quote competition, increased fragmentation, and negative abnormal returns following the implemen- 
tation of the new rules. Changes in trade aggressiveness and trading costs were not significant. NASDAQ stocks exhibit decreased trading costs and increased fragmentation following the implementation of the new rules, yet changes in quote competition were not significant. These changes reflect the nature of the new regulations. If the NYSE specialist can be ignored, competition inside the spread may decline. For NASDAQ listings, the new regulations indicate that trading costs have improved for pilot phase stocks and may reflect the impact of new price protection measures under the new rules.

Our results differ from Chung \& Chuwonganant (2012), who found quoted and effective spreads increased, quoted depth decreased, and the market quality index decreased after the implementation of the new rules. They found the new regulations were "detrimental to most traders". We conclude that the results are mixed. Our sample differs from Chung \& Chuwonganant (2012), as it separates NYSE and NASDAQ quotes and trades (rather than combining the two types of listings). The changes imposed on the NYSE market were unlike the changes imposed on the NASDAQ market. The size, industry types and volume of the two samples are also significantly different. In addition, we isolate trades subject to the new rules, as opposed to all trades, including F-trades ${ }^{1}$, which were not subject to the same provisions under the new rules. Chakravarty, Jain, Upson and Wood (2009) found that F-trades are widely used (46\% of trades and $41 \%$ of volume), and that inter-market sweep orders (FTrades, ISO trades) have significantly larger effective spreads than nonISO trades. A significant number of trades in our sample are designated as F-trades (12-13\% of the total trades). We believe the inclusion of Ftrades creates a negative bias in Chung \& Chuwonganant's results.

The new regulations were designed to modernize and strengthen the technological infrastructure used by the markets. The previous structure gave the NYSE specialist a 30-second option to execute incoming orders, creating a distinct opportunity, allowing the specialist to assess quoting behavior in other markets, meet or beat the best price, and capture 


\section{The BRC Academy Journal of Business Vol. 6, No. 1}

the trade. The lag in trading caused technical problems for electronic communication networks (ECNs) whose trading platforms required highspeed execution and electronic access. To eliminate this inequity, the SEC stipulated that only automated quotes would be protected under the new rules, in effect eliminating the specialists' advantage.

Beyond the electronic connectivity issues, the new regulatory structure was designed with the intention of eliminating the inconsistent application of the Order Protection Rule. Previously, price protection applied to NYSE/AMEX listings, but not to NASDAQ listings. The Order Protection Rule required brokers, dealers and other market makers to execute trades at the best available price in the national market at the time of the trade, or to route trades to the venue posting the best price. To address this inequity, it was felt that the SEC could either eliminate the Order Protection Rule altogether or extend it to all listings ${ }^{2}$.

This paper is organized as follows: Section 2 examines the new rules in greater detail; Section 3 explains the testable predictions; Section 4 describes the data and sample construction; Section 5 describes the various tests and methodologies; Section 6 provides the results; Section 7 contains concluding remarks and notes future research opportunities.

\section{SECTION 2: SEC REgulation NMS}

The SEC was charged by the United States Congress (1975) to facilitate the establishment of a National Market System (NMS). Congress directed the SEC to use the opportunities created by electronic processing and communications technologies to strengthen the securities markets.

The recent changes to NMS were a result of mounting pressure from the electronic markets to equalize the rules that favored the traditional exchange operations. After several years of public debate and extended comment periods, the SEC adopted the new rules in June of 2005 under Regulation NMS. The new rules were gradually phased-in over the period October 2006 to October 2007. 
Rule 610 (Access Rule) sets new standards governing access to quotations in NMS stocks ${ }^{3}$. It promotes access to quotations in two ways. First, it enables the use of private linkages to improve and facilitate access to quotations (rather than dictating a collective-linkage-facility as done under the Intermarket Trading System (ITS)). Second, Rule 610 limits the fees that any trading center can charge for accessing its protected quotations to no more than $\$ 0.0003$ per share.

Rule 611, the Order Protection Provision, establishes intermarket protection to prohibit trade-throughs for all NMS stocks. Rule 611 specifies that quotes must be immediately and electronically accessible. As a result, manual quotes posted by the specialist can be ignored for trade routing purposes. Rule 611 also equalizes the application of the tradethrough provision to all national market stocks, including NASDAQ stocks. SEC Chairman William H. Donaldson recognized the rule's importance: "[Shortly after announcing our intentions] ... the major floor-based exchanges announced plans to significantly increase the volume of electronic trading in their markets. The profound affect that this development will have on established ways of doing business on the floor-based exchanges has perhaps been underappreciated in the debate over the trade-through rule." ${ }^{4}$

The Commission adopted the re-proposed market alternative that protects only the national best bids and offers (NBBO) of the selfregulatory organizations (SROs) ${ }^{5}$ whose members currently trade NMS stocks. When an investor sends an order, the market maker can either execute the order at the NBBO, or route the order to the market that is quoting the best price. In response to Rule 611 most market venues and brokers have designed specialized trade algorithms and new order types to help investor's trade post-NMS.

Rule 611 includes three important exemptions. The first is called an Intermarket Sweep Order (ISO). As described by the SEC:

ISOs can be used to achieve a variety of trading objectives, including both the sweep of multiple price levels and a best-price routing 
strategy. By marking an order as an ISO, the router indicates to the destination-trading center that it has simultaneously routed additional ISOs, as necessary, to any better-priced protected quotations. When the limit price of an ISO is equal to or better than the NBBO at time of order receipt, there can be no betterpriced quotations elsewhere, and the router is simply seeking an order execution at the best displayed price or better. In contrast, when the limit price of an ISO is inferior to the NBBO at time of order receipt, the customer is effectively instructing the trading center that it can execute the order at a price inferior to the NBBO, even if one or more trading centers are displaying better prices. This instruction constitutes a request for special handling at the trading center that excludes the ISO from the definition of covered order in Rule 600(b)(15). The execution prices of such excluded ISOs are likely to be inferior to the execution prices of orders with the same limit prices that are not ISOs. http://www.sec.gov/ divisions/marketreg/nmsfaq605.htm

The ISO enables trading centers to execute orders immediately, without waiting for better-priced quotations in other markets to be updated. Rule 611 provides two additional exceptions for quotations experiencing a material delay in providing a response to incoming orders, as well as for flickering quotations with prices that have been displayed for less than one second. Both exceptions serve to limit the application of Rule 611 to quotations that are truly automated and accessible.

Many market centers ${ }^{6}$ as well as certain dissenting SEC Commissioners ${ }^{7}$ (Glassman \& Atkins, 2005) believed that Rule 611 was unnecessary and anticompetitive. Commissioners Glassman and Atkins cite a SEC study, ${ }^{8}$ which documents overall trade-through rates on NYSE and NASDAQ of $7.2 \%$ and $7.9 \%$. According to Glassman and Atkins, the study failed to account for two exemptions to the ITS trade-through provisions and once corrected, trade-through rates dropped to $1.2 \%$ for NYSE and $1.9 \%$ for NASDAQ stocks. They found that the trade-throughs amount to less than $1 / 100^{\text {th }}$ of one percent of the dollar value of trading on both markets. 
Atkins and Glassman (2005) argued that the trade-through provision would allow dealers to trap (or tie up) order flow by using the NBBO provision to prevent full competition among orders. Using ISOs, dealers are only required to match the best price at the posted depth and can then sweep the book at inferior prices. They argue that the new rules could lead to less quote competition at the inside (less depth) increasing overall trading costs.

\section{Section 3: Testable Predictions}

We examine changes in quote competition, trade aggressiveness, trading costs (spreads and returns), and volume as a result of the new regulations.

The null hypothesis is:

- $\mathrm{H}_{0}$. Quote competition, trade aggressiveness, trading costs, returns, or volume will remain unchanged following the pilot phase period implementation of the new rules.

- $\mathbf{H}_{\mathrm{A} 1}$. Quote competition will decline, trading costs will rise, and returns will decline following the implementation of the new rules.

NASDAQ listings are subject to the trade-through provision. Previous work suggests that the trade-through provision is anti-competitive leading to increase trading costs. In addition, the Rule 610 permits the electronic exchange operations to ignore slow quotes (the specialist) for trade-through compliance. Previous work indicates that the specialist has historically provided the best quotes and lowest execution costs for all NYSE listings (Nimalendran and Petrella (2003), Venkataraman and Waisburd (2005)). If the specialist is unable to compete for trades, market quality may decline. The existing literature points to some of these dilemmas. Previous studies find that the specialist is relatively more efficient and cost effective than the dealer market that is more 
dispersed (Christie \& Huang (1994), Huang \& Stoll (1996), Laplante \& Muscarella (1997))

- $\mathrm{H}_{\mathrm{A} 2}$. Quote competition will increase, trading costs will decline, and returns will increase following the implementation of the new rules.

Previous work suggests that trades outside the best quotes are more prevalent for NASDAQ listings (Chung, Van Ness \& Van Ness (2002)). Rule 611 requires all trades to be executed at the best available quotes. As a result, trading costs may decline and thereby improve market quality. Previous work suggests that competition improves market quality when electronic markets are able to compete (Weston (2002), Fink, Fink \& Weston (2006)). For NYSE listings, the specialist had a competitive advantage preventing the electronic markets from directly competing for trades. Rule 611 allows the electronic markets to ignore the specialist and should therefore improve competition and market quality for NYSE listings.

\section{Section 4: Sample Selection and Data}

We examined stocks chosen for the pilot phase implementation period of the new rules (event date July 9th, 2007). The primary listing market in consultation with the SEC selected the stocks, to be "reasonably representative securities". These stocks represent diverse industries including technology, healthcare, restaurants, banking, retail, manufacturing, oil and gas, communications, utilities, transportation, pharmaceuticals, wholesale, insurance, real estate and services. The samples represent the size characteristics of each market: The NYSE sample includes 55 large caps, 27 medium caps, and 5 small caps and the NASDAQ sample includes 3 large caps, 29 medium caps, and 62 small caps. The two samples are vastly different in terms of size, industry concentration, number of quotes and trades, and other descriptive statistics. The two samples are also 
vastly different in terms of the resulting impact imposed by the new rules. Combining the samples is not considered as a result of these differences.

We constructed two control samples consisting of stocks not participating in the pilot phase study. The control samples are compiled by matching each pilot phase stock to a control stock based on industry, market capitalization, stock price, and average daily traded shares. ${ }^{9}$

Stock quotes, trade prices, trade volume, number of trades, and trade size are extracted from the New York Stock Exchange's Trade and Quotes (TAQ) database. A total of 486,682,109 quotes and 81,251,618 trades are extracted from the database for all sample stocks. Only trades and quotes that are time stamped during regular NYSE trading hours (9:30 am to 4:00 $\mathrm{pm})$ is used in the sample resulting in the elimination of 225,694 trades and 7,525,087 quotes from the sample. In addition, a total of 73,442 trades and 16,155,252 quotes were eliminated on the basis of several error filters. ${ }^{10}$ Overall, the quote codes result in 29 quote eliminations and the trade codes result in 73,428 trade eliminations. Other practices in the literature (Bessembinder, 2003; Chung Van Ness \& Van Ness, 2002) remove all price/size quotes and trades less than or equal to zero (8,949,372 quote eliminations, 14 trade eliminations) as well as all quotes with spreads (Ask price - Bid price) greater than 4 or less than zero (crossed) resulting from timing errors $(7,205,851$ quote eliminations).

One additional filter is used to eliminate trades not subject to the new regulations. The code ( $\mathrm{F}$ as described in Appendix $\mathrm{H}$ ) identifies Intermarket Sweep Orders (ISO), or trades that are exempt from full trade-through compliance. This code was not commonly used until the new regulations went into effect on March 5, 2007. This exemption to the trade-through provision allows brokers as well as exchange operations to legally trade outside the quotes without violating the inter-market tradethrough rule (see Appendix F: Goldman, Sachs \& Co. Policy Statement). Brokers generally use ISO's to fill orders, when insufficient depth exists at the NBBO. In either case, the broker agrees to be responsible for best 
execution. These trades are excluded from the trades file for purposes of analysis (12\% of NYSE trades, $13 \%$ of NASDAQ trades).

The pilot phase implementation date (Monday, July 9, 2007) coincides with three other dates that may have an influence on the data and therefore, on the results. The first date of concern is the National Independence Day that occurred on Wednesday, July $4^{\text {th }}$ of the previous week. The second date of concern is the previous Friday, July $6^{\text {th }}$, which marked the beginning of the elimination of the uptick rule related to short sale transactions. A third is related to the US credit market meltdown which occurred during the summer of 2007. Since this study involves not only the pilot phase sample of stocks, but also the matching sample of stocks, any system wide variations as a result of the holiday and the elimination of the uptick rule, should be discernible in these samples.

\section{SECTION 5: Methodology}

The pre-phase period of analysis includes 5 trading days prior to the event date and 5 days following the event date for a total of 11 days of analysis. Q-Q plots for the file indicate the normality assumption is violated. As a result, median differences and related non-parametric tests (the sign test and the Wilcoxon test) are used. Non-parametric results are distribution free tests. ${ }^{11}$ On occasion the resulting medians are the same while the sign and Wilcoxon test indicate significant change. This result may occur when there is a change in the distribution rather than a change in location of the median. This situation arises in some of the tables, but is relatively infrequent in occurrence.

To capture changes surrounding the event date, four pre/post pairings are created. The first pairing compares medians during the period 5 days before and 5 days after the event date. The second pairing compares medians 3 days before and 3 days after the event date. The third pairing compares medians 1 day before and 1 day after the event date. The fourth pairing compares medians 1 day before to the event day, day 0 . In 
addition, the data for both the pilot and the matching sample is further divided into three time periods: from market open at 9:30 am to 10:00 am; from 10:00 am to 3:30 pm; and from 3:30 pm until market close at 4:00 pm. ${ }^{12}$ The second time slice is considered most relevant for assessing the impact of the new rules due to the volatility of trading patterns at the beginning and the end of the day.

The TAQ quotes file contains only the best quotes that occur at each time stamp by market. We adopt the same convention as others in this line of research (Bessembinder, 2003), and recognize the last quotation reported in the database as the quote going forward in time. The National Best Bid of Offer (NBBO) is constructed at each time stamp. The best bid quote can come from one venue and the best ask quote from another. It is also possible to construct a negative, or crossed NBBO, as a result of the construction and selection process. These NBBOs are dropped from the group. ${ }^{13}$

Once the NBBO is established, changes in quoting behavior can be studied. During each pairing/time slice, the following information is assessed for the quotes: 1) the percentages of time the quotes are at both the best bid and the best ask; 2) the percentage of time the quotes are at the best bid (but not best ask); 3) the percentage of time the quotes are at the best ask (but not the best bid); 4) the percentage of time the quotes are outside the best bid and offer; 5) the percentage of time the quotes are alone at both the best bid and ask; 6) the percentage of time the quotes are alone at the best bid only; and 7) the percentage of time the quotes are alone at the best ask only.

Multiple measures are calculated to assess the trade's file. Median pairwise differences are calculated on trade volume, average trade size and average trade price. Median pair-wise differences are also determined for 1) the percentage of buy trades; 2) the percentage of sell trades; 3 ) the percentage of trades inside the NBBO; 4) the percentage of trades outside the NBBO; 5) the percentage of buy trades at the ask price; and 6) the percentage of sell trades at the bid price. 
Two measures are used to assess execution costs: the quoted halfspread and the effective half-spread. Spreads are stated in both absolute terms and percentage spreads since spreads may vary with the level of stock prices. For each stock-day, the quoted half-spread (\$ and \%) and the effective half-spread ( $\$$ and \%) are determined. Following Bessembinder \& Venkataraman (2007) the quoted half-spread, $\mathrm{QS}_{\mathrm{it}}$ is defined as

$$
\mathrm{QS}_{\mathrm{it}}=(\text { Askit }- \text { Bidit }) / 2
$$

or as a percent:

$$
\% \text { QSit }=100 *(\text { Askit }- \text { Bidit }) /\left(2^{*} \text { Mit }\right)
$$

where Askit and Bidit are the posted NBBO ask price and bid price for security $i$ at time $t$, respectively, and Mit, the quote midpoint or mean of Askit and Bidit, is a proxy for the true underlying security value.

For many trades, the quoted spread is just a starting point for negotiations between buyers and sellers trading securities, and many trades occur at prices inside and also outside the posted quotes (Ready, 1999) ${ }^{14}$. A better measure of trading costs when trades occur either inside or outside the quotes is the effective half-spread and the percentage effective half-spread, which is based on the actual trade price. The effective halfspread is calculated as:

$$
\text { ESit }=\text { Dit }^{*}(\text { Pit }- \text { Mit }) / 2
$$

or as a percent:

$$
\left.\% \text { ESit }=100^{*} \text { Dit * (Pit }- \text { Mit }\right) /\left(2^{*} \text { Mit }\right)
$$

where Pit is the transaction price for security $i$ at time $t$, Dit is an indicator variable that equals one (1) for customer buy orders and negative one (-1) for customer sell orders, ${ }^{15}$ and Mit is the midpoint used as a proxy for the true underlying value of security $i$ at time $t$. The effective half-spread calculates the difference between the actual price and the true underlying value of the security. It can also be viewed as an estimate of the actual cost paid by traders and the gross revenue earned by liquidity 
providers. The Dit indicator is determined as follows: if the trade is more than the NBBO quoted midpoint ((Bid + Ask $) / 2)$, the trade is marked as a buy. If the trade is less than the midpoint, the trade is marked as a sell. If the trade is at the midpoint, the trade is marked according to the tick rule: If the trade is above (below) the previous price, then it is a buy (sell). If there is no price change but the previous tick change was up (down), then the trade is a buy (sell) (Lee and Ready, 1991). For each stock, a trade-weighted quoted spread and a trade-weighted effective spread is calculated following Chung, Van Ness and Van Ness (2002) and Stoll \& Schenzler (2006). An average of all stocks is then computed for each day of the sample period.

As an alternative test, an event study is conducted to assess wealth changes in NYSE and NASDAQ stocks that participated in the pilot phase period for trade-through compliance. An efficient framework to explore the effects of Rule 611 is the dummy-variable regression model introduced by Karafiath (1988):

$$
\mathrm{R}_{\mathrm{i}, \mathrm{t}}=\alpha_{\mathrm{i}}+\beta_{\mathrm{i}} \mathrm{R}_{\mathrm{m}, \mathrm{t}}+\gamma \mathrm{D}_{\mathrm{i}, \mathrm{t}}+\varepsilon_{\mathrm{i}, \mathrm{t}}
$$

$\mathrm{R}_{\mathrm{i}, \mathrm{t}}=$ return to security $i$ on observation $t$

$\alpha_{i}=$ the ordinary least squares (OLS) estimate of the intercept

$\beta_{i}=$ the ordinary least squares (OLS) estimate of the slope or measure of systematic risk

$\mathrm{R}_{\mathrm{m}, \mathrm{t}}=$ the return on the market on observation $t$

$\gamma=$ the estimated coefficient on dummy variable $D_{i, t}$, or abnormal return to security $i$ on observation $t$

$\mathrm{D}_{\mathrm{i}, \mathrm{t}}=$ a dummy variable that is equal to one on observation $n$ and is zero elsewhere

$\varepsilon_{\mathrm{i}, \mathrm{t}}=$ the residual for security $i$ on observation $t$.

The equation developed above is estimated for the event period in a single step over the $\mathrm{T}+\mathrm{N}$ observations in the estimation period $(100$ 
days prior to the event period). The event period includes 15 days before and 15 days after the event date of July 9, 2007 for a total of 31 days. Each $\gamma_{i, t}$ coefficient will be equal to the actual minus forecast value, or the abnormal return for each observation in the event period (Karafiath, 1988). An additional modification to the regression includes a correction for heteroscedasticity using the Newey-West modification, which corrects standard errors to account for heteroscedasticity.

Output from the regressions includes all excess returns ' $A R_{\mathrm{jt}}$ ' (the $\gamma_{\mathrm{i}, \mathrm{t}}$ coefficient for each observation). Similar to the Boehmer, Musumeci \& Poulsen (1991) test statistic, the estimate used to determine the $t$-statistic is

$$
t_{\mathrm{BMP}}=\mathrm{A} \sqrt{\mathrm{n}} / \mathrm{s}
$$

where $A$ is the average of the standardized abnormal returns $\left(\mathrm{SAR}_{\mathrm{it}}\right)$ over each event day of $n$ firms. The $\mathrm{SAR}_{\mathrm{it}}$ is equal to the ARit divided by (or standardized by) the standard deviation. The SAR is calculated for all firms ( $i$ ) over all days in the event window (matrix of standardized returns). $S$ is the standard deviation of the standardized abnormal returns. Event study methods that are based on using standardized abnormal returns outperform studies based on non-standardized returns (Kolari and Pynnonen, 2005), especially when volatility is a concern.

Traditional event study methodology assumes that the abnormal returns are not cross-sectionally correlated. This assumption is only valid when the event day is not common to the firms in the sample. If the event day is the same for all firms, a situation referred to as clustering is said to occur. The event day is common to all firms in this sample, and several firms are within the same industry as well. ${ }^{16}$ As a result, the test statistic above can understate the standard errors and can lead to severe over-rejection of no-event-effect when it is true (Type I error). In the event of a rejection, an adjustment to the Boehmer, Musumeci \& Poulsen (1991) test statistic is necessary to account for clustering (Kolari and Pynnonen, 2005). This test statistic is defined as:

$$
t \operatorname{adj}_{\mathrm{BMP}}=t_{\mathrm{BMP}} \sqrt{ }\{(1-\mathrm{r}) /[1+(\mathrm{n}-1) \mathrm{r}]\}
$$


where $r$ is the average of the sample correlations of estimation period residuals. If the return correlations are zero, the modified statistic reduces to the original statistic.

\section{SECTION 6: ResUlts}

\section{Quotes}

Tables 1.1 through 1.8 describe the median results and non-parametric tests for the NYSE pilot phase and NYSE matching sample for four pairings: 5 days, 3 days, 1 day ( +1 to -1$)$ as well as 1 day ( +0 to -1$)$. Tables 1.9 through 1.16 describe the median results for the NASDAQ pilot phase and NASDAQ matching sample for the four pairings.

\section{NYSE}

Overall, there is a decrease in the number of quotes at the best quotes and an increase in the number of quotes outside the best quotes for many of the pairings and time slices. Volume of shares at the best quotes also declined while volume outside increased. The pilot samples indicate a decrease in quote competition during the first and second time slice. The matching sample is stronger at end of the day, during the third time slice. In some respects, the results reflect the differences between the two platforms. The electronic markets are limit order markets whereas the specialist market is an auction based market. Limit order traders play a different role than specialists who have the responsibility to provide liquidity. Limit order traders have no such responsibility.

\section{NASDAQ}

Overall, the differences between the two samples are fairly weak, with the exception of the first time slice. There is clearly a decrease in quote competition related to the matching sample that is not evident in the pilot. NASDAQ pilot stocks are now subject to the trade-through provision under the new rules. Evidence in the first time slice for the 5- 
days pairings, indicates some stability in the quoting behavior. Since the pattern reverses for the matching sample during the second time slice, it is unclear whether this difference is meaningful.

\title{
Trades
}

Tables 2.1 through 2.8 describe the median results and non-parametric tests for the NYSE pilot phase and NYSE matching sample for four pairings: 5 days, 3 days, 1 day $(+1$ to -1$)$ as well as 1 day $(+0$ to -1$)$. Tables 2.9 through 2.16 describe the median results for the NASDAQ pilot phase and NASDAQ matching sample for the four pairings.

\section{NYSE}

Overall, there is no evidence of a change in trade aggressiveness or in trading costs as a result of the new rules for the NYSE stocks in the pilot phase or matching sample.

\begin{abstract}
NASDAQ
Trading costs for pilot phase sample stocks have decreased while changes in matching sample stocks were not significant. Evidence supports the hypothesis that the new rules have improved trading costs for NASDAQ listings.
\end{abstract}

\section{REGRESSIONS}

A series of event studies were conducted to assess the effectiveness of the new rules on the stocks participating in the pilot phase implementation period. Returns for the regressions were obtained from the CRSP database over the period January 22, 2007 through July 30, 2007. The estimation window covers a 100-day period prior to the event window, and the event window covers the period 15 days before and 15 days after the start of the pilot phase trade-through implementation period starting on July 9, 2007 (event date). 
The results for the NASDAQ pilot phase are in Table 3.1. Mid-Cap firms (between $\$ 1$ billion and $\$ 8$ billion; $\mathrm{n}=29$ ) and the Small-Cap firms (less than $\$ 1$ billion; $n=62$ ) are also reported in Table 3.1. Since the NASDAQ pilot phase sample has only three (3) large cap firms, regression results are not calculated for this sub-sample.

For the full, mid-cap and the small-cap sample, positive abnormal returns were obtained on the event day, but results were not significant. Cumulative abnormal returns (CARs) are negative for all other time frames. However, only the CARs on the full sample and the small-cap sample for timeframe up1 - up15 are statistically significant.

The results for the NYSE pilot phase sample are reported in Table 3.2. The Large-Caps ( $\$ 8$ billion or greater; $n=55$ ), Mid-Caps ( $\$ 1$ to $\$ 8$ billion; $n=27$ ), and the Small-Caps (less than $\$ 1$ billion; $n=5$ ) are also reported in Table 3.2 .

For the full sample, and all sub-samples, negative abnormal returns are observed on the event day as well as all other time frames following the event day. The CARs following the event day are negative for all samples and time frames, and the full sample and the Large-Cap sample are statistically significant starting at up1 - up5 and continuing to up1 - up15. The Mid-Cap sample is statistically significant at up1-up15, whereas the Small-Cap sample is statistically significant at up1- up10 and up1 - up15.

\section{VOLUme}

This section reviews the changes in US equity matched share volume over the period February 9, 2007 through July 7, 2011. The trade volume information is available on-line at www.batstrading.com and originates from the Consolidated Tape. Table 4.1 summarizes the changes in volume from February 9, 2007 to July 7, 2011. 
As shown, trade volume has grown over the four + year period (30\% in total); however, the percentage of trades from off-exchange to exchange operations increased 5\%. Most of this is due to the change in the status of the two ECNs (BATS and EDGE) from off-exchange to official exchange operations.

As shown, the NYSE market volume decreased by $15 \%$ (almost half of their volume), with an offsetting increase of $11 \%$ at BATS $8 \%$ at EDGE. Clearly, the new rules have dramatically altered the NYSE market's ability to attract and compete for order flow.

Specific information regarding the changes in NYSE and NASDAQ volume by exchange is detailed in Tables 4.3 and 4.4.

As shown, the NYSE and NASDAQ listings are increasingly fragmented and the order flow is spread more evenly across 5 major markets. Although the NYSE and NASDAQ exchange operations still control the bulk of the order flow for their listings ( $25 \%$ and $28 \%$ respectively), the electronic markets are now able to compete.

\section{Concluding Remarks}

In this study, we examine aspects of Regulation NMS imposed by the SEC on the US equities market in 2007. The new rules were designed to enhance competition for equity securities among markets by improving access and by equalizing the application of price protection measures. We examine changes in quote competition, trade aggressiveness, trading costs, volume and abnormal returns during the pilot phase implementation period of the new price protection measures for both NYSE and NASDAQ stocks that were subject to the new rules.

We find that NYSE stocks exhibit less quote competition, increased fragmentation, and negative abnormal returns following the implementation of the new rules. Changes in trade aggressiveness and trading costs are not significant. There is a decrease in the number of quotes at 
the best quotes and an increase in the number of quotes outside the best quotes for many of the pairings and time slices. Volume of shares at the best quotes also declined while volume outside increased. Although the trade data is less conclusive and the median spreads appear unchanged, negative abnormal returns are observed on the event day as well as all other time frames (significant at up1 - up5 and higher). Furthermore, long-term trends in volume reveal dramatic shifts away from the floor to the electronic markets following the change in the rules. Overall, the results indicate that the rules have had a negative effect on the pilot phase sample NYSE stocks.

For the NASDAQ samples, results do not indicate a radical change in quoting behavior. Trading costs, however, indicate a significant change and it appears as though the implementation of the trade-through provision improved spreads for the pilot phase stocks in the sample. Positive abnormal returns were obtained on the event day, but only the CARs on the full sample and the small-cap sample for time frame up 1 up 15 are significant. In terms of volume, competition among markets for NASDAQ listings has also increased and the order flow is more dispersed.

To address the first question put forth in this study, "Did the SEC balance the competitive powers among market venues?" the answer would be yes. With regard to the second questions, "Did the SEC improve the price protection available to investors?" the answer is less clear. More research involving quoting behavior, trading costs and the corresponding welfare effects is necessary. Short-term results surrounding the pilot phase would suggest that the concerns expressed by SEC Commissioners' Glassman and Atkins were unfounded. For NASDAQ listings the opposite occurred and trading costs declined. Further study of the long-term effects of the new rules on trading costs is necessary to address Glassman's and Akin's concerns.

The benefits of trading in electronic markets are unclear. Uncertainty exists as to whether the new electronic paradigm significantly benefits investors and the capital formation process. The academic literature 
regarding the role of the various markets, the difference among listings and among traders, is outdated in the context of electronic trading. There is a growing body of research regarding the impact on trading costs and market competition of off-exchange trading (dark markets/crossing markets and other ECNs not formally listed as exchange operations). This dynamic research area will continue to challenge those with an interest in microstructure research and electronic capital markets for years to come.

\section{REFERENCES}

Bessembinder, H. (2003). Quote-based competition and trade execution costs in NYSE listed stocks. Journal of Financial Economics, 70, 385-422.

http://dx.doi.org/10.1016/S0304-405X(03)00168-5

Bessembinder, H. \& Venkataraman, K. (2007). Bid-Ask Spreads: Measuring Trade Execution Costs in Financial Markets. Encyclopedia of Quantitative Finance, March 2009.

Boehmer, E., J. Musumeci, and A. B. Poulsen, 1991, Event study methodology under conditions of event induced variance. Journal of Financial Economics, 30, 253-272.

http://dx.doi.org/10.1016/0304-405X(91)90032-F

Brown, S. J. \& Warner, J. B. (1980). Measuring security price performance. Journal of Financial Economics 8, 205-258.

http://dx.doi.org/10.1016/0304-405X(80)90002-1

Brown, S. J. \& Warner, J. B. (1985). Using daily stock returns: The case of event studies. Journal of Financial Economics 14, 3-31.

http://dx.doi.org/10.1016/0304-405X(85)90042-X

Christie, W. \& Huang, R. (1994). Market structures and liquidity: A transactions data study of exchange listings. Journal of Financial Intermediation, 3, 300-326.

http://dx.doi.org/10.1006/jfin.1994.1008 
Chung, K. and Chuwonganant, C. (2012). Regulation NMS and Market Quality. Financial Management, Vol. 41(Issue 2),Summer 518-317

http://dx.doi.org/10.1111/j.1755-053X.2012.01184.x

Chung, K., Van Ness, B., \& Van Ness, R. (2002). Spreads, depths, \& quote clustering on NYSE \& NASDAQ: Evidence after the 1997 SEC rule changes. The Financial Review, 37, 481-505.

http://dx.doi.org/10.1111/1540-6288.00025

Chakravarty, S., Jain, P., Wood, R. and Upson, J. (2009). Clean Sweep: Informed Trading Through Intermarket Sweep Orders). Available at SSRN: http://ssrn.com/abstract=1460865 or http://dx.doi.org/10.2 139/ssrn. 1460865

Ellis, K., Michaely, R., \& O'Hara, M. (2000). The accuracy of trade classification rules: Evidence from Nasdaq. Journal of Quantitative Analysis, 35, 529-552.

http://dx.doi.org/10.2307/2676254

Fink, J., Fink, K., Weston, J. (2006). Competition on the Nasdaq and the growth of electronic communication networks. Journal of Banking and Finance, 30(9), 2537-2559.

http://dx.doi.org/10.1016/j.jbankfin.2005.10.009

Foster, F.D. \& Viswanathan, S. (1990). A Theory of Interday Variations in Volumes, Variances and Trading Costs. Review of Financial Studies, Vol. 3, 593-624.

http://dx.doi.org/10.1093/rfs/3.4.593

Gerety, M. S. \& Mulherin, J.H. (1992). Trading Halts and Market Activity: An Analysis of Volume at the Open and the Close. Journal of Finance, Vol. 5, 1765-1811.

http://dx.doi.org/10.1111/j.1540-6261.1992.tb04682.x

Glassman, C., \& Atkins, P. (2005, June 9). Dissent of Commissions Cynthia A. Glassman and Paul S. Atkins to the Adoption of Regulation NMS. Retrieved July 24, 2008 from https://www.sec.gov/rules/final/34-51 808fr.pdf pages 37632-37644. 
Hendershott, T., \& Jones, C. (2005). Island goes dark: Transparency, fragmentation, and regulation. The Review of Financial Studies, 18, 743-793.

http://dx.doi.org/10.1093/rfs/hhi013

Huang R., \& Stoll H. (1996). Dealer versus auction markets: A paired comparison of execution costs on NASDAQ and the NYSE. Journal of Financial Economics, 41, 313-357.

http://dx.doi.org/10.1016/0304-405X(95)00867-E

Karafiath, I. (1988). Using dummy variables in the event methodology. The Financial Review, 23(3), 351-357.

http://dx.doi.org/10.1111/j.1540-6288.1988.tb01273.x

Kolari, J. \& Pynnonen, S. (2005). Event study methodology: Correction for cross-sectional correlation in standardized abnormal return tests. Downloaded from http://www.uva.fi/fi/research/publications/ publicationseries/old/kolari_pynnonen_fullpaper.PDF

LaPlante, M. \& Muscarella, C.J. (1997). Do institutions receive comparable execution in the NYSE and Nasdaq Markets? A transaction study of block trades. Journal of Financial Economics, 45, 97-134.

http://dx.doi.org/10.1016/S0304-405X(97)81614-5

Lee, C. \& Ready, M. (1991). Inferring trade direction from intra day data. Journal of Finance, 46, 733-746.

http://dx.doi.org/10.1111/j.1540-6261.1991.tb02683.x

McInish, T.H. \& Wood, R.A., (1990). A Transactions Data Analysis of the Variability of Common Stock Returns During 1980-1984. Journal of Banking and Finance, Vol. 14, 99-112.

http://dx.doi.org/10.1016/0378-4266(90)90038-4

Nimalendran, M. \& Petrella G., (2003). Do 'thinly traded' stocks benefit from specialist intervention? Journal of Banking and Finance 27, 1823 $-1854$.

http://dx.doi.org/10.1016/S0378-4266(03)00103-1 
Stoll, H., \& Schenzler, C. (2006). Trades outside the quotes: Reporting delay, trading option or trade size? Journal of Financial Economics, 79, 615-653.

http://dx.doi.org/10.1016/j.jfineco.2005.03.006

Venkataraman, K., \& Waisburd, A. (2005). The value of the designated market maker. Journal of Financial and Quantitative Analysis. SSRN: http://ssrn.com/abstract $=881585$

http://dx.doi.org/10.2139/ssrn.724941

Weston, J. (2002). Electronic communication networks and liquidity on the Nasdaq. Journal of Financial Services Research, 22 (1\&2), 125-139. http://dx.doi.org/10.1023/A:1016072905438

Wood, R., McInish, T., \& Ord, J. (1985). An Investigation of Transaction Data for NYSE Stocks. Journal of Finance. Vol. 40, 723-739.

http://dx.doi.org/10.1111/j.1540-6261.1985.tb04996.

\section{Citation Information}

Wright, Susan, Howard Nemiroff, and Jim Owens. "An Empirical Analysis of New Rules Adopted Under Regulation National Market System: Pilot Phase Period Implementation Results." The BRC Academy Journal of Business 6, no. 1 (2016): 89-113. http://dx.doi.org/10.15239/ j.brcacadjb.2016.06.01.ja04

\section{Web Appendix}

A web appendix for this paper is available at:

http://dx.doi.org/10.15239/j.brcacadjb.2016.06.01.wa04 


\section{Notes}

1. F trades indicate an Intermarket Sweep Order: ISO trades occur when an exchange sweeps its book without checking for a trade through. The broker agrees to be responsible for best execution. These trades were first reported on February 8, 2007, but were not commonly used until Reg. NMS went into effect on March 5, 2007.

2. It was this aspect of the new regulations that created the greatest controversy. Although two SEC commissioners and many market participants opposed the extension of the Order Protection Rule, the SEC proceeded with the extension and the new rule was equally applied to all equity listings.

3. The NMS encompasses the stocks of more than 5000 listed companies which represent more than \$14 trillion in US market capitalization. (Federal Register/Vol. 70, No. 124/Wednesday, June 29,2005/Rules and Regulations, p. 37497)

4. Statement by SEC Chairman: Opening Statement at Commission Open Meeting of April 5, 2006, Re: Regulation NMS.

5. Self-Regulatory-Organizations ("SROs") include the following exchanges: American Stock Exchange; Boston Stock Exchange; CBOE Stock Exchange; Chicago Stock Exchange; International Stock Exchange; NASDAQ Stock Market, LLC; National Stock Exchange; NYSE and NYSE Arca, Inc.; and the Philadelphia Stock Exchange.

6. See http://sec.gov/spotlight/regnms.htm for several written responses to trade-through provision requirements established under new REG NMS.

7. http://sec.gov/rules/final/34-51808-dissent.pdf

8. SEC Release No. 34-51808 page 37507

9. Additional details regarding the samples are presented in Appendices A, $\mathrm{B}, \mathrm{C}$ and $\mathrm{D}$

10. These error filters are commonly used in the literature (Bessembinder, 2003; Chung, Van Ness \& Van Ness, 2002; and Huang \& Stoll, 1996). Several errors are easily identified in the TAQ database and TAQ Quote Codes 4, 7, 9, 11, 13, 14, 19, 20, 27, \& 28 and TAQ Trade Codes 2, 7, 8, 9, 10,11 , and 12 as well as codes A, C, D, N, O, R and Z are also eliminated.

11. See Appendix I for details regarding the formulae and assumptions related to the various statistical tests used in this study. 
12. Early empirical research on intra-day patterns finds high variance of returns at the beginning and at the end of the trading day (McInish and Wood, 1990 and Wood, McInish and Org, 1985). Foster and Viswanathan (1990) find a U-shaped pattern in the variance of price changes by hour of the day. Jain and Joh (1988), Foster and Viswanathan (1990), and Gerety and Mulherin (1992) find evidence of a U-shaped pattern in intra-day volume.

13. In this study, $0.19 \%$ of the pre-phase NBBOs were crossed and $0.20 \%$ of the post-phase NBBOs were crossed. See Appendix J, Crossed NBBOs with Volume for more detailed information regarding crossed NBBOs.

14. Electronic markets have hidden limit orders that are entered at prices inside the NBBO. The Nasdaq market recently disclosed that $20 \%$ of their order flow is non-displayed. Retrieved November 15, 2008 http://www. nasdaqtrader.com/Trader.aspx?id=DarkLiquidity

15. Following Bessembinder (2003), trades are designated as reflecting customer buy or sell orders using the algorithm recommended by Ellis, Michaely, and O'Hara (EMO, 2000). As recommended by EMO and by Bessembinder (2003), trades are compared to quotes in effect at the trade report time, without any adjustment to time stamps to allow for possible reporting delays. Bessembinder (2003) tests his results by allowing for trade reporting lags ranging from 5 to 20s. (Lee and Ready, 1991, recommend a 5s delay.) Bessembinder (2003) reports that adjusting trade time stamps did not alter any of the conclusions reported and reports results based on a zero time-stamp adjustment.

16. Brown and Warner $(1980,1985)$ show that even in the case when the event day is common, if the firms are not from the same industry, cross correlations reduce to zero. They also employ the market model to conduct the event study rather than the regression technique used in this study. 
